\title{
AVALIAÇÃO DO PROCESSO ADSORTIVO UTILIZANDO RESIDUOS DE Fragaria vesca (MORANGO) PARA REMOÇÃO DE COR EFLUENTE TÊXTIL
}

Willian Geraldo da Silva - williang18@ hotmail.com

Centro Universitário Patos de Minas-UNIPAM

Ana Carolina Martins Matos- anacarolina.mm@ outlook.com

Centro Universitário Patos de Minas-UNIPAM

Ludimila Lucas da Silva- ludimilalucas@ hotmail.com

Centro Universitário Patos de Minas-UNIPAM

Wagner Marques Oliveira Junio- wagner1grupo@ hotmail.com

Centro Universitário Patos de Minas-UNIPAM

Tiago José Vieira- tj.vieira01@gmail.com 


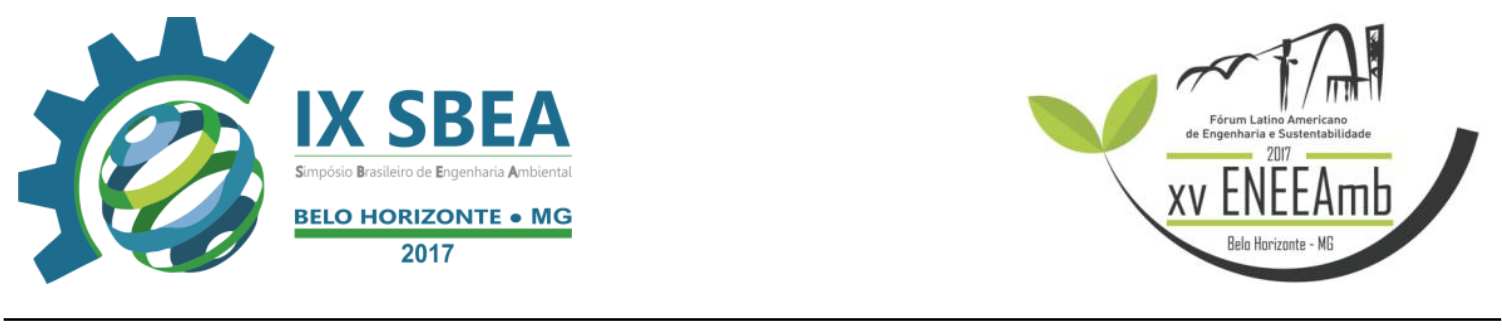

\section{RESUMO}

O presente trabalho objetivou avaliar a potencialidade dos resíduos de Fragaria vesca (morango) como biossorvente no tratamento de efluente têxtil bruto. No estudo foi determinado o ponto de carga zero, tamanho da partícula, influência do $\mathrm{pH}$ e caracterização do efluente. A eficiência do processo foi avaliada em função da redução de cor e da remoção de matéria orgânica, como DBO. Os testes foram realizados com o material in natura. Os resultados demostraram que a superfície da biomassa apresentou ponto de carga zero entre a faixa de $\mathrm{pH}$ de 6,5 a 7,5. A biomassa estudada possui uma alta eficiência na remoção do corante com granulometria ajustada para 18 mash no pH ajustado para 2, removendo até $97,13 \%$ de cor em meio aquoso. Foi empregada a análise estatística ANOVA e o teste de Tukey utilizando o software SISVAR ${ }^{\circledR}$. Foi realizado análise da DBO nas amostras dos efluentes brutos e após tratamento a fim de comparar com parâmetros da legislação. Assim, o material mostra-se eficiente na remoção de cor em efluentes têxteis.

\section{Palavras-chave: Bioadsorção; Biomaterial; Morango.}

\section{INTRODUÇÃO/OBJETIVO}

Os efluentes têxteis caracterizam-se por serem altamente coloridos, já que a tecnologia moderna no tingimento consiste de dúzias de etapas que são propostas de acordo com a natureza da fibra têxtil. O processo de tintura envolve como operação final uma etapa de lavagem em banhos correntes para retirada do excesso de corante original ou corante hidrolisado não fixado à fibra nas etapas precedentes (GUARATINI e ZANONI, 2000).

A eliminação de tais efluentes nas redes de esgoto comum pode causar grandes problemas, o que exigiriam procedimentos muito mais drásticos, sensíveis e caros para identificação e remoção específica destes corantes (GUARATINI E ZANONI, 2000). Devido às implicações ambientais, novos processos de remoção e/ou degradação destes compostos em efluentes têxteis têm sido testados (ANDRADE, 2003). Alguns desses métodos alternativos que vêm sendo investigados são, por exemplo, eletrodiálise, osmose reversa, ultrafiltração e o carvão ativado como adsorvente na remoção de corante, porém trata-se um método oneroso (BONIOLO, 2008). 


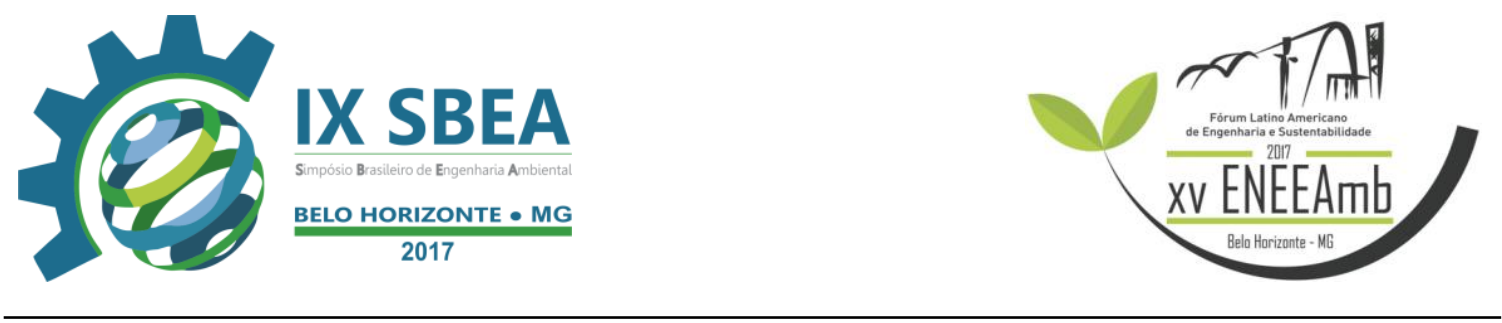

A fim de reduzir o alto custo dos processos de adsorção, a bioadsorção vem se destacando como método alternativo, uma vez que utiliza resíduos que seriam rejeitados, na remoção de contaminantes orgânicos. (ROCHA, et al., 2012). A bioadsorção é um fenômeno físico-químico de adesão essencialmente de superfície, observado quando um componente de uma fase líquida ou gasosa é transferido para a superfície de um sólido. No processo de adsorção ocorre a diminuição da energia livre superficial, liberando ou absorvendo uma quantidade definida de calor (JESUS, 2012).

Assim, o presente trabalho tem como objetivo avaliar as propriedades adsortivas dos resíduos de morango visando o tratamento de efluente de indústrias têxteis, a fim de subsidiar a proposição de alternativas de tratamento com viabilidade econômica comparado aos sistemas físico-químicos tradicionais.

\section{MATERIAL E MÉTODOS}

\subsection{COLETA E PREPARO DA BIOMOSSA DE MORANGO}

A biomassa de Fragaria vesca (morango) utilizada nesse trabalho é um resíduo que foi fornecido pela Frutpres Empresa de beneficiamento de polpa de frutas, localizada na cidade de Presidente Olegário, região do Alto Paranaíba (Minas Gerais) e posteriormente encaminhados para o Laboratório de Engenharia Química do Centro Universitário de Patos de Minas (UNIPAM). Após a obtenção do material, o mesmo foi disposto à secagem natural por 24 horas. Feito isso, foram levados para estufa, para uma secagem completa com temperatura de $50^{\circ} \mathrm{C}$, onde permaneceram por $72 \mathrm{~h}$ ou até alcançar massa constante e, posteriormente, o material foi triturado em um liquidificador industrial. Em seguida, passou-se por um processo de peneiramento onde a granulometria que ficaram retidas nas peneiras de 18 e 28 mash foram utilizadas.

\subsection{COLETA DOS EFLUENTES E CARACTERIZAÇÃO DO EFLUENTE}

Os ensaios foram realizados com amostras coletadas de uma indústria têxtil localizada na cidade Patos de Minas/MG. As mesmas foram coletadas em recipientes de polietileno, transportadas e armazenadas em um refrigerador à $4^{\circ} \mathrm{C}$ no Laboratório de Química Geral do Centro Universitário de Patos de Minas (UNIPAM), para que as 
características físico-química da mesma sejam preservadas ao máximo possível durante o processo de analítico.

\subsection{ESTUDO DA ADSORÇÃO}

O comprimento de onda de máxima absorbância do efluente foi determinado através de varredura em espectrofotômetro Thermo Spectronic. Em seguida, foram realizadas as leituras do efluente bruto em cubetas de vidro com comprimento de onda máximo determinado.

Foram realizadas as leituras das amostras após o tratamento com o material orgânico, com o valor de absorbância do efluente bruto e as leituras das amostras, assim realizado o seguinte cálculo para avaliar a \% de remoção, conforme Equação 1:

$$
\text { Descoloração }(\%) \equiv(\text { Absi- Amo }) \times 100
$$

(Equação 1)

\section{Absi}

Em que: $A_{b s i}=$ Absorbância do efluente bruto; $A_{m o}=$ Absorbância da amostra

Esse procedimento de cálculo de porcentagem de remoção foi utilizado durante todos os testes do presente trabalho. Assim, garante-se que as variações são relacionadas apenas a remoção e não a variação de leitura diária do equipamento.

\subsection{OTIMIZAÇÃO DOS PARAMETROS QUE AFETAM A ADSORÇÃO}

Para avaliação dos parâmetros que afetam a adsorção, os ensaios foram realizados em batelada. As amostras dos efluentes foram transferidas para erlenmeyer de 500ml, onde foram ajustados os pHs para intervalos pré-definidos de 2, 7 e 9. Foram submetidas ao ensaio três amostras do efluente com o biomaterial (resíduo de morango), variando a massa entre 3 e $20 \mathrm{~g}$, em triplicata, totalizando 36 amostras.

As amostras foram filtradas em papel filtro qualitativo. Logo após, foram retiradas alíquotas e encaminhadas ao espectrofotômetro, assim determinando o comprimento de onda de máxima de absorbância do efluente utilizado no trabalho. Após obter os valores pela varredura, calculou-se a descoloração do efluente por meio da Equação 1. 


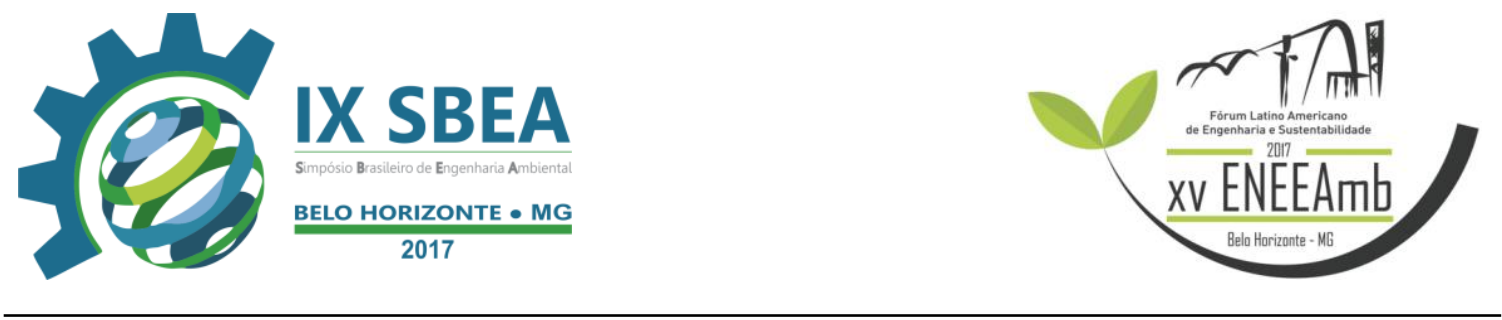

Os ensaios foram realizados em aparelho Jar-Test Analógico para 3 provas, Modelo JT-102/3 com agitação de 120rpm por 5 minutos, trocando a velocidade para 20rpm por 10 minutos. Para ajuste do $\mathrm{pH}$, foi utilizado soluções de $\mathrm{HCl}$ (ácido clorídrico) e $\mathrm{NaOH}$ (hidróxido de sódio) a 1,0 mol/L, com auxílio do phmetro Inatec.

\section{RESULTADOS E DISCUSSÕES}

\subsection{OTIMIZAÇÃO DOS PROCESSOS DE ADSORÇÃO}

Para avaliar a capacidade de remoção do efluente têxtil quando em contato com os resíduos de morango foram realizados testes em três diferentes de $\mathrm{pH}: 2,7$ e 9 e diferentes biomassas. O gráfico abaixo representa a porcentagem de remoção para a granulometria 18 .

Foi verificado a taxa de remoção para o meio ácido ( $\mathrm{pH}$ 2) com a granulometria ajustada para 18 mash com 3, 5, 7, 10, 15, $20 \mathrm{~g}$ da biomassa, como mostra a Figura 3.

Figura 3 - Diferentes quantidades $(3,5,7,10,15,20$ g) de resíduo de Fragaria vesca $L$. (morango) com granulometria ajustada para 18 mash, submetidas a processo de adsorção em batelada para identificação da taxa de remoção de cor em efluente têxtil bruto em diferentes pHs (2, 7, 9). UNIPAM - Patos de Minas, 2016.

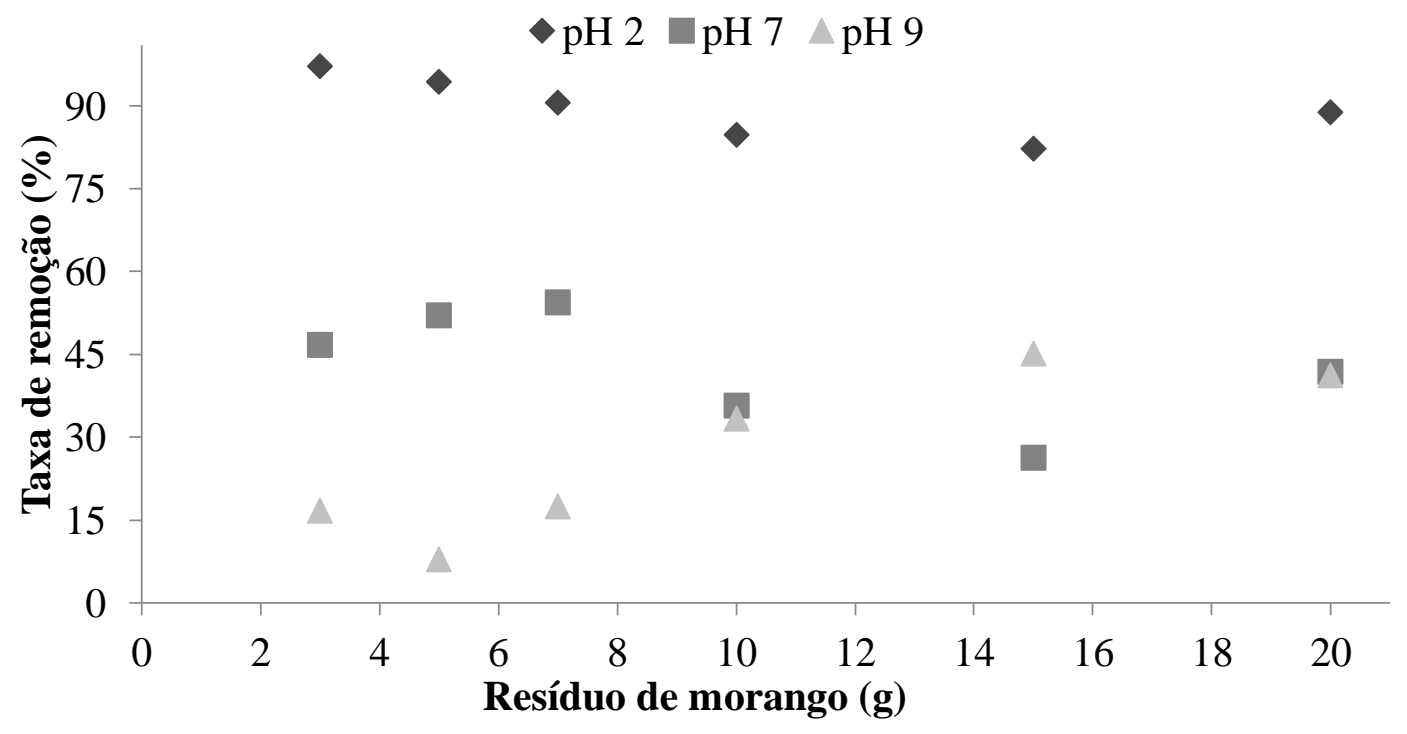

Após o processo adssortivo com a biomassa, foi observado que as amostras que possuíam o meio mais ácido $(\mathrm{pH}$ 2) obtiveram maiores resultados para remoção de cor 


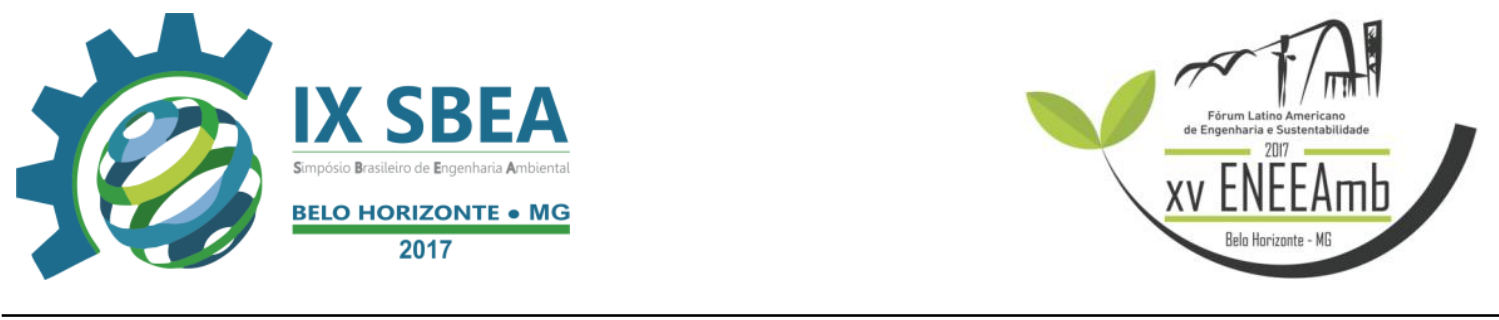

no efluente têxtil, de acordo com avaliação visual. A solução se mostrou com eficiência de remoção superior neste $\mathrm{pH}$ com granulometria de 28 mash. Os resultados mostram que a quantidade ideal para o maior teor de remoção $(97,1351 \%)$ foi de $3 \mathrm{~g}$. Assim, os resultados inferem que quanto maior a quantidade de biomaterial no processo de adsorção, menor será a taxa de remoção, visto que a solução ficou saturada, reduzindo a superfície de contato entre o efluente e o os poros do biomaterial.

Para a avaliação estatística da influência das variáveis testadas pHs (2, 7 e 9) para granulometria (28 mash), realizou-se a Análise de Variância (ANOVA) dos valores obtidos no experimento através do Software SISVAR. A Tabela 1 apresenta essa análise.

Tabela 1 - Análise de Variância (ANOVA) para remoção do efluente (\%) em função do pH (2,7e 9) para granulometria 28 mash com nível de confiança de $95 \%$

\begin{tabular}{|c|c|c|c|c|c|}
\hline FV & GL & SQ & QM & $F_{\text {tratamento }}$ & $F_{\text {tabelado }}$ \\
\hline Tratamentos & 2 & 12747.21957 & 6373.60978 & 51.7176 & 6.3589 \\
\hline Resíduo & 15 & 1848.58122 & 123.23875 & & \\
\hline Total & 17 & 14595.80079 & & & \\
\hline
\end{tabular}

Como $F_{\text {tratamento }}(51,71)$ é maior do que o $F_{\text {tabelado }}(6,35)$, a hipótese que afirma que os grupos testados $(\mathrm{pH})$ não influenciam na quantidade de corante adsorvida é rejeitada, ou seja, existem diferenças na quantidade do efluente bruto removido pelos diferentes $\mathrm{pHs}$ testados.

A existência de três grupos testados, faz-se necessário compará-los para determinar quais apresentam diferenças significativas entre si. Para este procedimento, foi utilizado o Teste de Tukey, com nível de confiança de 95\% no Software SISVAR. O resultado se encontra da Tabela 2 .

Tabela 2 - Teste de Tukey para comparação entre as médias dos diferentes pHs (2,7 e 9) na adsorção do efluente têxtil com nível de significância de $95 \%$.

\begin{tabular}{c|c}
\hline \multicolumn{2}{c}{ Médias de tratamento } \\
\hline 1 & $89.63361 \mathbf{a}$ \\
\hline 2 & $42.83565 \mathbf{b}$ \\
\hline 3 & $26.93744 \mathbf{b}$ \\
\hline
\end{tabular}




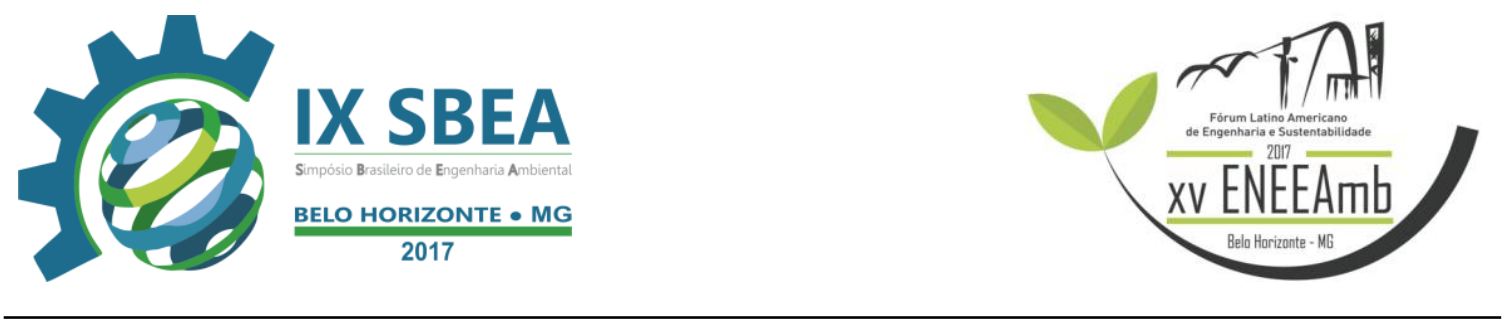

As médias seguidas pela mesma letra não diferem estatisticamente entre si. Assim, as médias em negrito para o tratamento com granulometria de 28 mash indicam que existem diferenças significativas entre os respectivos tratamentos. Desta forma, o tratamento 1, o qual foi realizado em um ambiente ácido $(\mathrm{pH} \mathrm{2})$, se mostrou melhor estatisticamente.

Silva et al., (2010) em seu estudo com pseudocaule de bananeira como biomassa bioadsorvente têxtil azul de remazol $\mathrm{R}$ encontrou um pH ótimo de remoção 2, os autores observaram que quanto maior era o $\mathrm{pH}$ menor se tornava menor eficiência, explanando a dependência do pH ácido para uma melhor remoção.

Os dados obtidos no processo adsortivo com o tamanho da partícula em 18 mash vem para reforçar os resultados encontrados com a granulometria 28 mash. Assim, a maior taxa de remoção de cor do efluente têxtil para 28 mash foi superior nas quantidades de 3,5 e 7 gramas de material empregadas no processo, todas no mesmo meio ácido, como mostra a Figura 4.

Figura 4 - Diferentes quantidades $(3,5,7,10,15,20$ g) de resíduo de Fragaria vesca (morango) com granulometria ajustada para 28 mash, submetidas a processo de adsorção em batelada para identificação da taxa de remoção de cor em efluente têxtil bruto em diferentes pHs

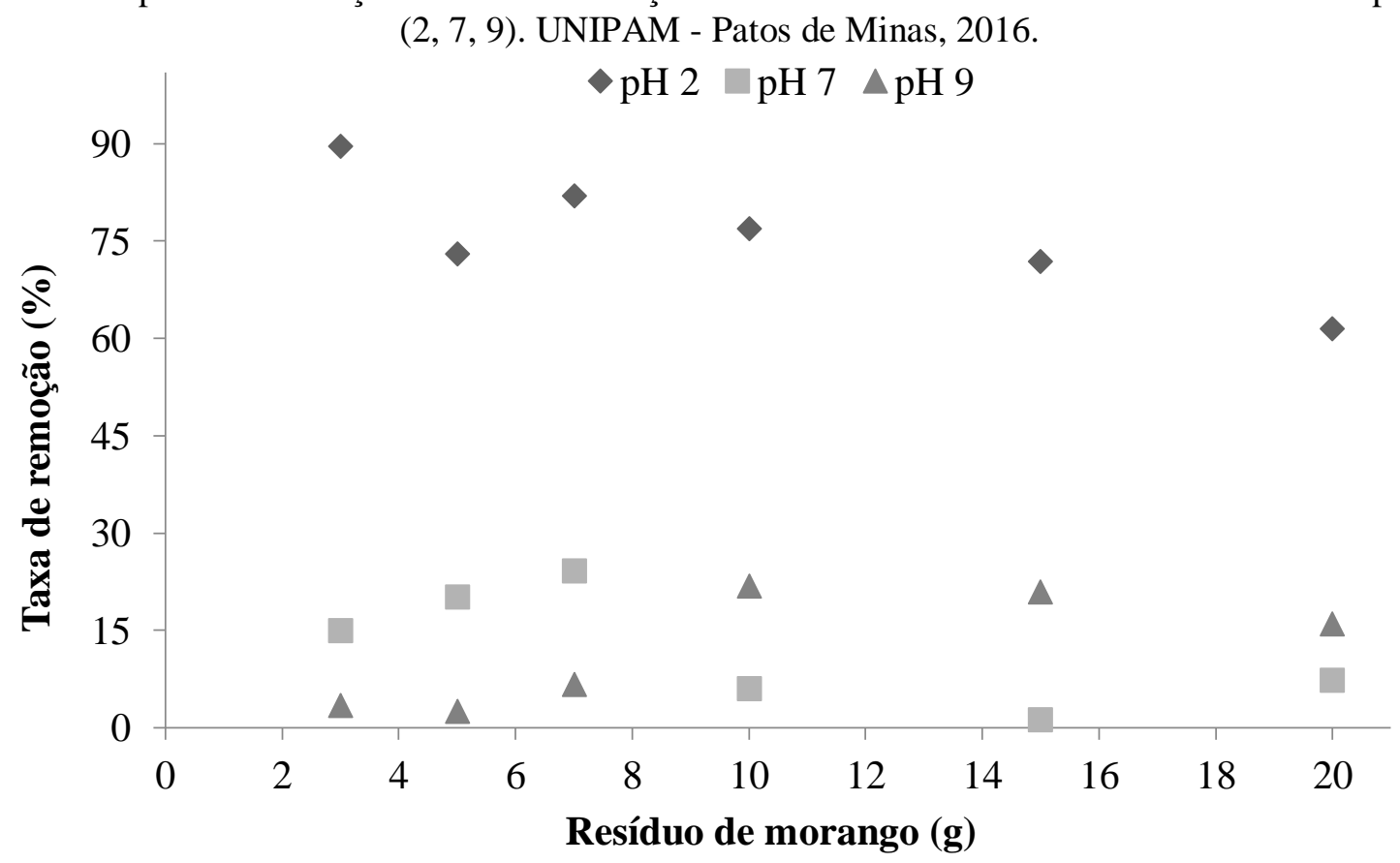




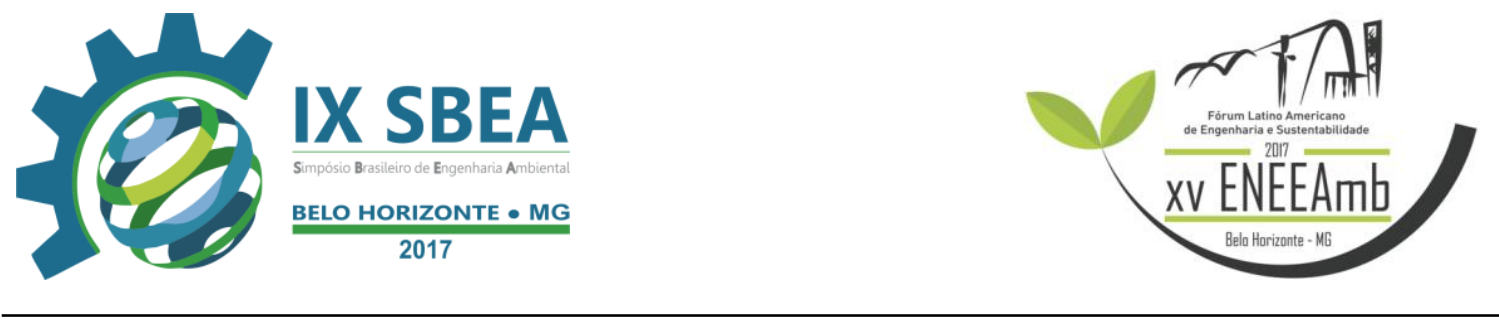

Observando o gráfico acima, o pH ótimo de adsorção foi o 2, que resultou em uma remoção de $89,57 \%$ do efluente têxtil utilizando o resíduo de morango in natura como biomassa adsorvente. Ainda, observando no gráfico a remoção, em pHs mais básicos (7 e 9), diminuiu drasticamente. É importante ressaltar que para o pH considerado ótimo nesse estudo, não foi observado nenhuma variação na solubilidade dos componentes orgânicos da biomassa utilizada, bem como o efluente têxtil utilizado.

Partindo dos dados obtidos, foi efetuado um estudo estatístico do processo, em que se realizou a Análise de Variância (ANOVA) do Software SISVAR. A estatística da influência das variáveis testadas pHs (2,7 e 9) para granulometria (28 mash) estão apresentados na tabela abaixo.

Tabela 3 - Análise de Variância (ANOVA) para remoção do efluente (\%) em função do pH (2,7e 9) para granulometria 18 mash com nível de confiança de $95 \%$

\begin{tabular}{llllll}
\hline FV & GL & SQ & QM & F $_{\text {tratamento }}$ & F $_{\text {tabelado }}$ \\
\hline Tratamentos & 2 & 16238.24970 & 8119.12485 & 98.1110 & 6.3589 \\
Resíduo & 15 & 1241.31708 & 82.75447 & & \\
\hline Total & 17 & 17479.56678 & & & \\
\hline
\end{tabular}

**Significativo ao nível de $1 \%$ de probabilidade $(p<.01)$.

*Significativo ao nível de $5 \%$ de probabilidade $(.01=<p<.05)$.

$\mathrm{FV}=$ Fonte de variação, $\mathrm{GV}=$ grau de liberdade, $\mathrm{SQ}=$ soma de quadrado, $\mathrm{QM}=$ quadrado médio, $F=$ teste $F F_{\text {tratamento }}$ de Fisher (variância entre os tratamentos).

Como $F_{\text {tratamento }}(98,1)$ é maior do que o $F_{\text {tabelado }}(6,35)$, a hipótese que afirma que os grupos testados $(\mathrm{pH})$ não influenciam na quantidade de corante adsorvida é rejeitada, ou seja, existem diferenças na quantidade do efluente bruto removido pelos diferentes pHs testados. Apesar da grande variabilidade inerente aos processos utilizando biomassas residuais, a análise estatística foi considerada satisfatória, com um intervalo de confiança de $95 \%$ p $(<0,05)$, assim demostrando que a regressão obtida não é apenas significativa, mas também, útil para fins de preditivos.

Dessa forma, pode ser rejeitada a hipótese de nulidade. Deve existir, pelo menos um contraste significativo entre as médias de tratamentos, em relação aos pHs testados. Como existem três grupos testados, faz-se necessário comparar os mesmos para determinar quais apresentam diferenças significativas entre si. Para este 
procedimento, foi utilizado o Teste de Tukey com nível de confiança de 95\% no Software SISVAR. O resultado se encontra da Tabela 4.

Tabela 4 - Teste de Tukey para comparação entre as médias dos diferentes pHs (2,7 e 9) na adsorção do efluente têxtil com nível de significância de $95 \%$.

\begin{tabular}{l|l}
\hline \multicolumn{2}{l}{ Médias de tratamento } \\
\hline $\mathbf{1}$ & $75.77465 \mathbf{a}$ \\
\hline $\mathbf{2}$ & $12.25215 \mathbf{b}$ \\
\hline $\mathbf{3}$ & $11.86948 \mathbf{b}$ \\
\hline
\end{tabular}

As médias em negrito para o tratamento com granulometria de 18 mash indicam que existem diferenças significativas entre os respectivos tratamentos. Desta forma, o tratamento 1, o qual foi realizado em um ambiente ácido ( $\mathrm{pH}$ 2), se mostrou melhor estatisticamente.

Royer (2008), observa também que a remoção do corante vermelho reativo 194 não-hidrolisado na casca de semente de araucária angustifólia diminuiu drasticamente com o aumento dos valores de $\mathrm{pH}$ de 2,5 a 6,0, e que para valores de $\mathrm{pH}$ maiores que 4,5, a adsorção do corante foi praticamente anulada.

Ströher et al. (2012), utilizando o mesmo efluente deste estudo, proveniente de da lavagem de jeans e o bagaço de laranja in natura como biomassa adsorvente para remoção de cor, encontrou o pH 3 como o ótimo para adsorção, assim confirmando com o pH ácido ideal para remoção cor.

\section{CONCLUSÕES/RECOMENDAÇÕES}

Os experimentos desenvolvidos mostraram que a casca de morango pode ser utilizada para remoção de cor, sendo este biossorvente uma boa alternativa, devido a sua viabilidade, já que os resíduos de morango não são reaproveitados industrialmente e seriam descartados. Assim, adotar o material como adsorvente seria de baixo custo e envolveria o conceito de sustentabilidade, fatores almejados nos dias de hoje quanto aos processos industriais.

\section{REFERÊNCIAS}

ANDRADE, F. Remoção de cor de efluentes têxteis com tratamento de lodos ativados e um polieletrólito orgânico. 2003. 121 f. Dissertação (Mestre em Engenharia Ambiental) - 


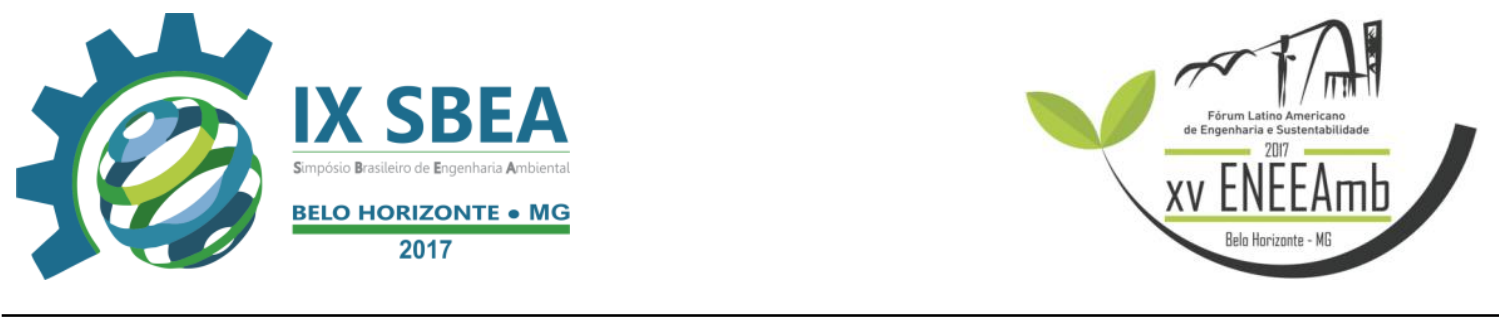

Programa de pós-graduação em engenharia ambiental, Universidade Federal de Santa Catarina, Florianópolis, 2003.

BONIOLO, M. R. Biossorção de urânio nas cascas de banana. 2008. 100 f.

Dissertação (Mestrado em tecnologia nuclear) - Centro de Química e Meio Ambiente, CQMA Instituto de Pesquisas Energéticas e Nucleares IPEN/CNEN-MCT, São Paulo, 2008.

GUARATINI, C. C.I; ZANONI, M. V. B. Corantes Têxteis. Revista Química. Nova, Vol. 23, No. 1, 71-78 2000.

JESUS, K. A. Estudo cinético e do equilíbrio da biossorção dos íons chumbo e cobre pela macroalga Sargassum sp. em sistemas monocomponente e binário. 2010.95 f. Dissertação (Mestre Engenharia Química) - Instituto de Química, Universidade do Estado do Rio de Janeiro, Rio de Janeiro, 2010.

ROCHA, O. R. NASCIMENTO, G. E. CAMPOS, N. F. SILVA, V. L. DUARTE, M. M. M. B. Avaliação do processo adsortivo utilizando mesocarpo de coco verde para remoção do corante cinza reativo bf-2r. Revista Química. Nova, Vol. 35, No. 7, 1369-1374, 2012.

ROYER, B. Remoção de correntes têxteis utilizando casaca de semente de araucária angustifólia como biosorvente. 2008. 65 f. Dissertação (Mestrado) - Instituto de química, Universidade Federal de Rio Grande do Sul, Porto Alegre, 2008.

STRÖHER, A, P. MENEZES, M. L. FIORENTIN, L. D. PEREIRA, N. C. Utilização do bagaço de laranja no tratamento de efluente proveniente da lavagem de jeans. e-xacta, Belo Horizonte, v. 5, n. 1, p. 27-37. (2012). 